\title{
PARESIS OF ACCOMMODATION FOLLOWING INJURY BY LIGHTNING
}

\author{
BY \\ J. Augustus Lea, \\ GRAHAMSTOWN, SOUTH AFRICA.
}

W. L., aet. 37 years, was struck by lightning. He was unconscious for a few moments, but did not fall, and for'a few minutes was unable to see.

When I saw him on the following day he was suffering from great pain in the eyes and photophobia; the conjunctiva of each eye was very red and congested. The skin of the eyelids was reddened, the eyelashes charred.

In about a week he recovered from the conjunctivitis. $\mathrm{He}$ returned after two weeks, complaining that he could no longer see to read properly with his glasses.

I had prescribed for him about three years before this time the following correction :

R.E. +0.75 D. Sph. $\subsetneq+0.25$ D. Cyl. ax. $80^{\circ}$ d. and i.

L.E. +1.0 D: Sph. $こ+0.25$ D. Cyl. : ax. $80^{\circ}$ d. and i.

With this correction he then read J.1 from $5 \frac{1}{2}$ inches to 20 inches with each eye singly.

When he came to see me this time he could not read No. J.1 nearer than $13^{\prime}$ inches with the left eye, and 9 inches with the right eye, showing slight irregular paresis of his ciliary muscles. He was also exceedingly nervous. . . : All conjunctivitis had disappeared, but the eyes were still irritable, and after reading a short time the sight became dim and the eyes painful.

He improved with weak eserin drops locally, and nux vomica internally, and then, having to leave for another part of the country, I lost sight of him.

\section{THE TREATMENT OF TRACHOMA}

BY

\author{
J. Augustus Lea, \\ GRAHAMSTOWN, SOUTH AFRICA.
}

AFTER reading the excellent paper by Captains Stukey, Tomlin, and Hughes in the issue of the BRITISH JOURNAL OF OPHTHALMOLOGY, of January, 1920, I am induced to call attention to a method of treatment of chronic trachoma which I recommended in a paper read before the-Fourth South African Medical Congress, and published in the South African Medical Journal, of August, 1898. 
Trachoma was formerly very prevalemt, more especially in the Karoo districts of South Africa; and I have had exceptional opportunities of seeing and treating cases during a long residence in this country. In the first place I may say that the appearances of the cases described in the paper of January, 1920, coincide with what I have observed in this country in every particular.

The method of treatment which I have used now during several years, and found very successful in chronic trachoma, is as follows.-I have an instrument made for me by Weiss, which is really a tattooing needle bent to almost a right angle at about $1.5 \mathrm{~mm}$. from the point.

After everting the upper eyelid, and washing with a saturated solution of boric acid, I instil a few drops of Darier's "CocaRenalin," I then dip the instrument in a mixture of equal parts of acid acet. fort., and distilled water, and prick each grey translucent granulation: then wash off the excess of acid with the boric solution.

If the granulations are very numerous and small, instead of pricking each granulation I scarify the granulations with the charged needle. The groove of the needle being filled with acid, like a pen with ink, each prick carries a little of the acid into the granulation. I find that after this treatment the true granulations disappear very rapidly.

The treatment causes little or no pain if Darier's weak solution of cocaine is used; and the reaction is very slight, unlike the pain and violent reaction usually met with after "expression."

For the treatment of hypertrophied papillae I have found that if there is a marked discharge the application of a 2 per cent. solution of nitrate of silver is the best. If the discharge is scanty or none at all, I find that the application of sulphate of copper is the best treatment.

But in using either of these applications I have found it advisable to limit the application to the granulations only, avoiding healthy conjunctiva. To do this in using the solution of nitrate of silver I apply with a minute camel hair pencil, neuturalizing with solution of sodium chloride.

When I apply the sulphate of copper I use a very fine point of the crystal, and as far as possible touch the granulations and nothing else, washing off excess of sulphate.

I got very good results in the treatment of hypertrophied papillae by using a 10 per cept. solution of argentamin; but, unfortanately, since the War I have been unable to obtain a fresh supply. 